\title{
INTERPRETING COMPOUNDS FOR MACHINE TRANSLATION
}

\author{
BARBARA GAWRONSKA \\ ANDERS NORDNER \\ CHRISTER JOHANSSON \\ CAROLINE WILLNERS
}

Dept. of Linguistics, University of Lund, Helgonabacken 12, S-223 62 LUND, Sweden

\section{SUMMARY:}

The paper presents a procedure for interpretation of English compounds and for automatic translation of such compounds into Slavic languages and Frencl. In the target languages, a compound nominal is as a rule to be rendered by an NP with an adjective or genitive attribute, or with an attributive participle construction. The model is based on I3ierwisch's theory of word formation, which in turn is inspired by categorial grammar. The procedure is applied to a specific domain (asthma rescarch).

\section{INTRODUCTION}

The need of a component interpreting complex lexical items in an MT system translating from Germanic languages into e.g. French or Slavic languages is obvious. Many rules (or patterns) of word formation are highly productive, which makes it impossible to store all complex lexical entries in a static lexicon.

An elfective MT system must also be able to match the interpretation of a complex entry with the correct morphosyntactic patlern in the target language. For example, a program translating from German into Polish must distinguish the relations between the parts of a compound like Universitätslehrer (university teacher) from the relations holding between Musik and Lefher in Musiklehrer (teacher of music). The first mentioned compound is to be tanslated ats a noun followed by an adjective (nanczyciel umiwersytecki-'teacher university+adjective ending'), the later one as a noun and a genitive attribule ( $n$ auczyciel muzyki-'teacher musictgen'). Similar' problems occur when translating into French or Czech: cf. Musikabend-Fr. soirée musicale (n a), C\%. hudebni večer (an n), Musiklehrer-lit. professeur de musique (n prep n), Cz. ucitel hudby (n $\mathrm{n}+\mathrm{gen})$.

The models for compound interpretation and generation proposed by general linguists (cf. Lees 1960, Selkirk 1982, Fanselow 1988, Bierwisch 1989) requite as a rule several modifications in order to be applicable in an MT system. Since, in our opinion, a model aimed to serve as an efficient tool for NLP and MT must be linguistically valid, we will discuss a number of theoretical questions and relate our model to general linguisties before presenting our experimental procedure for domainrestricted compound transhation.

\section{TIIE STATUS OF WORI HORMATION} RUIASS

1.1. 'Where's morphology?'

The above question, put by Stephen Anderson 1982, is still waiting for a definitive answer. Word formalion rules have been claimed to obey syntactic principles and hence being a part of UG (Lees 1960, Pesetsky 1985), to form a grammatical level on their own (Di Sciullo \& Williams 1987), to be explainable in semantic terms solely (Fanselow 1988) or to belong to the lexicon (Chomsky 1970, Jackendoll 1975, Bierwisch 1989).

We will propose a quile simple answer to Anderson's question: morphology shall be seen as a component of the grammat, the notion 'grammal' to be understood as an integrated model where no borders are drawn between syntix, morphology, and semantics.

\section{2. 'Towards an integration of syntax, semantics and morphology}

Fanselow (1985, 1988) argues, on the hasis of psycholinguistic evidence, for treating word formation rules not as generative processes, but as a 'primitive' process of concatenating morphemalic items, a very casily leamable procedure. His argumentation is restricted to morphology in the traditional sense of the term. We would like to go even further and claim that the grammar as a whote can be regarded as a sed of pattens for concallenation or coocurrence of lexical items, each concatenation pattern associated with principles of semantic interpretation. This approach is to some extent inspired by (but far from identical to) calcgorial grammar and Bierwisch's lexicon theory (Bicrwisch 1989). At the same time, it is in its very essence not incompatible with Constraint Grammal (Karlsson 1990), Koskemiemi 199()).

\subsection{Compounds as collocations}

English compounds provide an argument in favour of our approach to grammar. It seems impossible to draw a clear-cut horderline between strings traditionally labelled as 
compounds and those classilied as noun phrases. Cf. the lollowing examples, taken from a corpus of medical abstracts:

ragweed allergic rhinitis

house-dust-allergic asthma

house dust asthma

patient daily symptom diary cards

fluticasone propionate aqueous nasal spray

In most grammatical descriptions, strings consisting of nouns (like house dust asthma) are treated as compound nouns, whereas a complex including an adjective followed by a' noun is normally labelled as an NP. The above examples show, however, that such at distinction is not unproblematic. Phrases like house-dust-allergic asthma and fluticasone propionate aqueous nasal spray may be analysed either as NPs containing a compound adjective and a head noun, or as compounds including optional adjective constituents (house dust asthma and fluticasone spraty are perfectly well-formed). Furthermore, parts of an English compound may provide referents for elliptic constructions, as in the following examples:

The variations in provocation concentrations ... were small during both placebo and active drug treatment

the difference between a single allergen provocation and continuous exposure...

Thus, a noun included in a compound can still have a relerent on its own, an ability normally associated with nominal phrases. Such facts indicate that there is no absolute distinction to be drawn between compound nominals and complex nominal phrases in English. It seems more appropriate to talk about more or less lexicalized collocations. However, in the following the tritditional term 'compound' will be used.

\section{AUTOMATIC INTERPRETATION AND} TRANSLATION OF COMPOUNDS

\subsection{The theoretical foundation}

Bicrwisch (1989; ci also Olsen 1991) regards the process of compounding as a functional application, where one of the thematic roles of the head noun becomes 'absorbed'. For example, a noun like payer is supposed to have the following interpretation:

\section{$\lambda y \lambda x[z I N S T[x P A Y y]]$,}

where $y$ is the external theta-role, $x$ the internal one, and $z$ represents the 'referential role'. In a compound like bill payer, the internal role of pay becomes instantiated:

\section{$\lambda \times[$ INSST[XPAY BILL1]}

Our analysis of compounds is not incompatible with Bierwisch's approach. However, for the purpose of MT, a classification of valency in terms of threc kinds of theta roles only (external, internal and referential) seems insufficient. A procedure for compound interpretation must also take into account optional thematic roles, e.g. location (university teacher). It must in addition be able to deal with compounds that do not include deverbal components. Hence, we decided to modity the theory proposed by Bierwisch at two main points:

a. the valency of a verbal stem is to be represented not in terms of external and intemal theta roles, but in terms of the components of the event or situation the verb may refer to

b. the interpretation of compounds that do not contain deverbal elements is based on morphosemantic patterns specifying the delault readings of combinations that include members of different semantic caltegories.

\subsection{An experimental procedure for understanding derived nouns and compounds}

In an experimental program, implemented in I_PA MacProlog, we structured a very restricted lexicon of Swedish stems and allixes (basal lexical entries, BLA) according to the approach oullined above. Each verbal stem was provided with a list of elements of its typical event referent, c.g.:

lex([liir],m(teach,stem),v,vt, [agent, sem_object,domain,place, time, result|,[]).

Allixes were specilied with respect to the following features:

$\checkmark$ the calcgory or categories of stems the aflix may be combined with

$\checkmark$ the resulting caltegory, including the morphosyntactic specilication

$\checkmark$ the default semantic interpretation of the allix.

For eximple, the Swedish agentive sulfix -are was represented as:

slex ([are],suff(n,agr(sg,re, indef $)), v$, agent, [] $)$.

Underived nouns got a quite simplified semantic specifation formulated in traditional terms like 'human', 'animate', 'ahstract', 'concrete', 'potential location' ete. On this basis, the interpretation procedure tried to match the semantic specilication of the affix or of the noun and associate the morphematie entries attached to the verb stem with the most probable elements of 
the stem's semantic vallency. The program distinguished correctly between compounds like grammatiklairare (teacher of grammal) and tmiversitetslarare (university teacher), as shown in the following outprint.

$$
\begin{aligned}
& \text { :- analyse([grammatiklärare]) } \\
& \text { m(ldomain(grammar), } \\
& \text { head }(\mathrm{m} \text { (lagent(suli) } \\
& \text { head(tcach) I)) I) } \\
& \text { category: } 11 \text { agr(sg, re, indel) } \\
& \text { constitucnts [grammatik, lïrare, [lär, are]] } \\
& \text { :- analyse([universitetslitrare|) } \\
& \mathrm{m} \text { (Iplace(university), } \\
& \text { head( } \mathrm{m}(\operatorname{agent}(\operatorname{sulf}) \text {, } \\
& \text { head((cach)]))]) } \\
& \text { catcgory: } n \text { agr }(s g, n, \text { indel) } \\
& \text { constituents [universitet, lärare, [lï, arel] }
\end{aligned}
$$

The program was also able to inteperes somewhat unusual, but fully possible compounds like aniversitetsmörlare (univessity killer). In the case of "university killer", three alternative interpretations were given, all of them acceptable in Swedish: 1) a person who kills in university buildings, 2) somebody who causes destruction of a university, 3) somebody who uses a university for destructive purposes. The flexibility of the quite simple interpletation procedure and its ability to 'understand' even unusual complex words encouraged us to apply the method tested by meatss of the toy program for a more serious goal, viz. for interpretation and translation of medical abstrices dealing with asthma and allergy research.

2.3. Translation of compounds within a restricted domain (medical texts on asthma and allergy research)

\subsubsection{Domain-related requirements}

In order to construct a domain specific lexicon and to design appropriate parsing and translation algorithms, we investigated a corpus of about 140 medical abstracts. Already the preliminary inspection provided evidenee lor the need of a special procedure lor compound interpretation. The fiequency of compounds in the texts was extremely high. Cl. the following simple:

A large-scale multicenter investigation was undertaken in 3 cities with comparable pollen seasons and atmospheric pollen concentrations in order to obtain more definite information about the safety and efficacy of cromolyn sodium in the treatment of pollen-induced seasonal rhinitis.

Complex names of chemical substances, as cromolyn sodium, do not pose cspecially great problems to an MT system, since chemical symbols may be efliciently used as interlingual representations. Highly lexicalized and highly idiosyncratic compounds, like airways or hay fever, may also be stored in the basic lexicon. The main dillieulty lies rather in the translation of productive compounds referring to different allergic syndroms, types of medical treatment and paticnt groups (ragweed pollen asthma, late-summer thinitis, flunisolide test, flumisolide patient group etc.). In different texts, the same syndrom may be relerred to by different phrases, e.g. ragwood asthma, ragwood-induced asthma, ragwood pollen asthma, ragwood allergic asthma etc. A correct interpretation of the semantic relations between the eonstituents of such collocations is necessary for correct transtation. Otherwise, a phatse like childhood asthma would be translated into French not as asthme des enfants, but as asthme induit par enfance (lit. asthma induced by childhood-by analogy to e.g. pyrethrum asthmaasthme induit par pyréthrines). A procedure for interpretation of compounds and complex NPS must therefore include a kind of domain knowledge, preferably encoded in the lexicon.

\subsubsection{The lexicon}

An MT system ilimed at translation ol" scientilic texts should give the user a possibility ol adding new enlries to the lexicon in a simple way. A system lor medical ahstract translation would not be really uselul, il the user could not inlroduce names of new medicines, new terms denoling syndroms, symptoms, treatment methods elc. Since the users of such a system would, with a high degree of probability, be a non-linguist, the linguist designing the method for lexicon extension must adapt the form of interactions to the expected compelence of the user.

It would be naive to belive that a non-linguist could manage to specify the lexical items in terms of internal and external theta-roles. Even terms like agent, theme and semantic object would probably caluse conlusion. Hence, it secms most reasonable to formulate the semantic elassification in domain-specific texts (in our casc, in terms like allergen, syndrom, body-part etc.). 'There are actually linguistic reasons for this solution, as scientific sublanguages difler semantically from cach other as well as fiom the everyday conversation language. For a botanist, pyrehrum is primarily a plant belonging to the chrysanthemum lamily, whereas an allergy re- 
searcher regards pyrethrum as an allergy-inducing factor, having much in common with grass pollen and house dust.

In the preliminary model of the lexicon developed until now we classify nouns as members of the following categories:

- syndrom (asthma, rhinitis)

- symptom (sneezing, irritation)

- allergen (pyrethrum, ragwood)

- body part (airways, skin)

- body function (inhalation)

- chemical substance:

medicine (antihistamine) or not used as medicine (histamine)

- medical treatment (injection)

- scientific method (measurement, test)

- time period (season, childhood)

- human: patient or not (the later distinction is needed for correct interpretation of e.g. asthma patient and asthma researcher)

- amount: mass or countable (dose, group)

- others: concrete or abstract

\subsubsection{Interactive lexicon extension}

The user has the possibility to classily new nouns to be added to the lexicon by marking the desired alternative in an interaction window. The same entry may be marked as belonging to several categories. For example, inhalation may be regarded as both body function and medical treatment (house dust inhalation/steroid inhalation). When adding a compound, the user is asked to specily its constituents according to the category list above. New words may be typed in by the user or read in from a text file.

It is assumed that the lexical entries 10 be added will belong to open lexical clisses: nouns, verbs and adjectives. To distinguish between these three classes is not an impossible lask for a non-linguist, especially if an appropriate instruction is provided. Adjectives are classified in a way similar to nouns, c.g. nasal, bronchial-denoting body part; stuffy, runny (as in stuffy nose)-denoting sympiom and attribute of body part.

A user-adapted classification of verbs is more difficult to achieve. In our preliminary model, the user is presented questions combined with example patterns, for instance: 'Does the verb take an object, like investigate the effects?' 'Does it also take a complement with a certain preposition like: shield the patient from house dust?' 'What preposition is required?' If the verb in question turns out to be transitive, a further question is asked about the semantic category of the typical object, according to the standard catcgory list. "The specification of verbs takes more time than the one of nouns and adjectives. However, the need of introducing new verbs is qusually not as great as the need of adding new nouns.

\subsubsection{Compound interpretation and generation of target equivalents}

The present program covers the most frequent types of compounds found in the corpus. After having filtered out the most fiequent verbs (auxiliaries, modals) and items belonging to closed lexical classes (pronouns, articles, prepositions etc.), we first investigated word frequencies, and then the (unfiltered) environment of about the thirty most frequent words. On this basis, we could state that the most usual compounds containing the most frequent nouns (distegarding names of chemical substances) display the following patterns:

i. (attribute, concrete)-allergen-(adj)-syndrom

house dust (allergic) asthma

(grass) pollen (seasonal) asthma

ii. medicine/allergen-medical treatment

antigen injection

allergen injection

steroid treatment

iii. (time period)-ad j/allergen/medicine-

(body part)-scientilic method

allergen (skin) test

9 week double-blind study

iv. syndrom-patient-(countable amount)

hay fever patient group

v. medicinc-(paticnt)-countable amount

steroid patient group

llunisolick group

vi. body part-body lunction/symptom

skin hyperesponsiveness

airwaly palency

vii. (attribute, concrete)-allergen-time period

grass pollen season 
viii. (medicine/allergen)-medicall tratmenthody function-time period

steroid treatment period

house dust inhalation period

The procedure for compound interpretation is based on a Prolog formalization of the most frequent patterns. The following program fiagment shows what the format for basal lexical entries looks like and how the interpretation rules are constructed.

$\operatorname{lex}([a s t h m a], n,[$ syndrom $\mid, \ldots, \ldots)$. lex([dust],n, [allergen],_,,_). lex([pollen],n,[allergen|,_,_,_). lex([patient],n, [patient|,_,_,_). lex([scason],n,[time_period],.,.,.). lex(|steroid],n.|medicine|,_,_,_). lex(lgrass|,n, |concrete $\left.]_{, \ldots,+,}\right)$.

I* pattern: grass pollen */

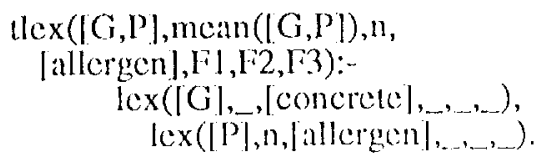

lex $=:$ hasic lexical entry

tlex $=$ temporary lexical entry
The rules simply specify the default interpretation of a sequence of nouns and deliver a semantic representation coded in 'Machinese English', as shown in the outprints below:

:- interpret([house, dust, asthma, patient])

mean(Ipatient, suffering from, syndrom (fasthma, beciuse_of,allergen([house, dust $\mid)[) \mid)$

grammatical callegory : 11

semantic citlegory: [patient]

:- interpret([house, dust, inhalation])

mean([inlsalation, of_object,

allergen(|house, dust|)|)

grammatical cattegory : $n$

semantic caltegory: [body_function]

The Machinesc representations can without difficulties be matched with the appropriate target morphosyntactic patterns. For example, the semantic representation of grass pollen asthma patient becomes associated with the Polish pattem (simplilied notation):

patient, suffering from,

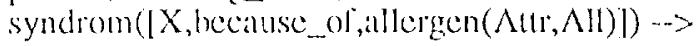

n(pallienl, $\wedge$ gr,nom), prtact(suller, $\Lambda \mathrm{gr}, n \mathrm{nom})$, prep(sulfer,Prep,Case), $n(X, A g r 2$, Case $)$, prtpass(cause, $\Lambda$ gr2, Case), n(allergy, $\wedge$ gr 3 ,ins), prep $(,$, nia,ack $)$, $\mathrm{n}(\Lambda \mathrm{ll}, \wedge \mathrm{gr}\}, \mathrm{ilck})$, $n(\Lambda \operatorname{tr}, \operatorname{agr}(\mathrm{Gen}, \mathrm{pl}), \mathrm{gen})$.

ins $=$ the instrumental case

The pattern above correctly generales the l'olish equivalent of grass. pollen asthma partent:

pacjent cierpiacy um astme patient suffering prep asthma-ace

spowodowanc

calused-ace

mazuleniemna pytek kwiatowy maw allergy-ins prep polien-ice flower-adj grass-gen

In a similar way, he program disambiguates ragwood asthma and childhood asthma when translating into French. Still, certain ambiguitics may remain: the present program can, for example, not decide whether grass pollen asthma should be lanslated into rench as asthme in- 
duit par pollen des graminées or par pollen de l'herbe. The decision has to be made by the user.

Translation of frequent compounds of the type noun+past participle (allergen-shielded, allergen-tested, placebo controlled) is handled in a way similar to the one used in the prototype program when translating compounds like university teacher and university killer. The semantic category of the noun is compared with the semantic specification of the valency of the verb stem and the noun is associated with the most probable verbal argument. Thus, allergen shielded room is interpreted as 'a room shiclded from allergen', while allergen tested shin gets the reading 'skin tested by exposure to allergen'.

\section{CONCIUSIONS AND IMPIICATIONS FOR FURTHER RESEARCH}

\subsection{Remaining problems}

The method proposed here has so far led to good translation results. However, the problem lics not only in interpreting a compound, but also in identifying an English word sequence as a compound. For the time heing, we use a parsing procedure based on a combination of dependency grammar and categorial grammatr. The main parsing difficulty, when dealing with an English input, is to decide whether a lexical stem functions as a linite predicate or as a nominal. We try to remove the ambiguity by starting the parsing by a procedure called 'verbtinder', searching for possible candidates for the predicate function. The function ol ambiguous items, like result, control elc., may olten be identilied on the basis of their evironment: if the word in question is immediately preceded by a preposition and/or an article, it can be easily identified as a nominal element. The parsing procedure may still be made more efficient by utilizing results of statistic investigations of the corpus (Steier \& Belew 1991, Johansson 1993).

\subsection{Future plans}

The advantage of the model outlined here lies in the lact that the general approach to the grammar underlying the translation system may be adapted to diflerent domains without violating any theoretical assumptions. However, the theory solely does not guarantee a high-quality translation. The preliminary system outlined above is to be developed and improved along the following lines:

$\checkmark$ statistical methods will be used in order 10 reduce ambiguities and to discover coocurrence patterns on the basis of larger corpora

0 the medical vocabulary will be enlarged by using latge computational medical data-bases (e.g. MEDLINE) and by consulting specialists who are native speakers of the languages in volved in the system

$O$ the interactive procedures will be evaluated and relined by testing their uselulness in experiments with non-linguists.

The results of the corpus investigations and the experiments with translation of abstracts are to be used in a system for automatic abstracting and multilingual abstract generation.

\section{REFERENCES:}

Anderson, S. 1982. Where's morphology? Linguistic Inquiry 13. pp. 571-612.

Bierwisch, M. 1989. Event nominalization: Proposals and problems. Motsch, W. (ed.): Wortstruktur und Satzstruktur. Berlin: VEB (=Linguistische Studien, Reihe $\wedge$ 194). pp. $1-73$.

Chomsky, N. 1970. Remarks on nominalizallions. R. Jacobs \& P. Rosenbaum (eds.): Readings in English Transformational Grammar. 184-221. Waltham: Ginn \& Co.

Di Sciullo, A.M. \& E. Williams. 1987. On the definition of word. Cambridge: MIT Press.

Fanselow, G. 1985. What is a possible complex word"? J. Toman (ed.): Studies in German Grammar. Dordrecht: Foris. pp. 289 318.

Fanselow, G. 1988. 'Word Syntax' and semantic principles. G. Booij \& J. v. Marie (eds.): Theorie des Lexikons. Universitat Diisseldort. pp. 1-32.

Jackendoli, R. 1975. Morphological and semantic regularities in the lexicon. Language 51. pp. 639-71.

Johansson, C. 1992. Using a statistical measure to lind relations belween words: Semantics fiom frequency of co-occurrence? (MS)

Karlsson, F. 1990. Constraint grammar lor parsing running kexts. Coling ' 90 , Helsinki. pp. $168-173$

Koskenniemi, K. 1900. Finite-state parsing and disambiguation. Coling '90, Helsinki. pp. 229-32.

Lecs, R. 1960. The grammar of English nominalizations. The Hague: Mouton.

Olsen, S. 1991. Zur Grammatik des Wortes: Argumente zur Argumentstruktur. Theorie des Lexikons. Universilät Düsseldort. pp. $31-58$.

Pesctsky, D. 1990. Experiencer predicates and universal alignment principles. Cambridge: MIT Press.

Selkirk, E. 1982. The syntax of words. Cambridge: MIT Press.

Steier, A.M. \& R.K. Belew. 1991. A statistical analysis of topical language. R. Casey \& B. Croli (eds.): 2nd Symposium on Document Analysis and Information Retrieval. 